\title{
Perception of Aesthetic Impairment in Patients With Systemic Sclerosis: A Case Control Study Using a Semi-Quantitative Scale for Body Image Assessment.
}

Méryem-Maud Farhat ( $\nabla$ meryem.farhat@chu-lille.fr )

University of Lille: Universite de Lille

Pierre Guerreschi

CHU Lille

Sandrine Morell-Dubois

CHU Lille Pôle Enfant: Centre Hospitalier Universitaire de Lille Pole Enfant

Valérie Deken

CHU Lille

Julien Labreuche

CHU Lille

Sébastien Sanges

CHU Lille

Vincent Sobanski

CHU Lille

Eric Hachulla

CHU Lille

Olivier Cottencin

CHU Lille

David Launay

CHU Lille

\section{Research article}

Keywords: Systemic sclerosis, visual aesthetic scale, body image assesment, perception of aesthetic impairment, self-esteem, self-evaluation

Posted Date: May 19th, 2021

DOI: https://doi.org/10.21203/rs.3.rs-526048/v1 
License: (c) (i) This work is licensed under a Creative Commons Attribution 4.0 International License. Read Full License 


\section{Abstract}

Background: Systemic sclerosis (SSc) is a fibrotic disease. Assessment of body image could be central in optimizing care. Yet, data are scarce. The main objective was to assess perception of aesthetic impairment using a visual aesthetic scale (AES) in patients with SSc compared to healthy subjects. Secondary objectives were to assess associations between perception of aesthetic impairment and standardized questionnaires for aesthetic impairment as well as clinical, psychological/quality of life, and functional parameters of SSc.

Methods: This study evaluated and compared perception of aesthetic impairment in two populations: patients with SSc, in a referral center at Lille Hospital, France, and healthy controls.

Results: This study included 88 patients (69 [78.4\%] women) with a median age of 52 years and 88 controls (49 [55.7\%] women) with a median age of 45 years. Perception of aesthetic impairment assessed using the AES was poorer in patients than in controls ( $3.7 \pm 0.3$ vs $2.8 \pm 0.3, p=0.028$ ), with statistical correlation with ASWAP. Patients with anxiety or depressive symptoms had significantly higher AES scores.

Conclusion: The AES appears to be an ease of use tool to evaluate body image. Correlations found with psychological and quality of life parameters reflect the importance of these parameters for body image evaluation and its complex assessment.

Trials registration: NCT03271320

\section{Introduction}

Systemic scleroderma (SSc) is a fibrotic autoimmune disease that mainly affects women between the ages of 40 and 60 with a prevalence in the general population estimated at between 50 to 200 cases per million (1). Fibrosis involvement of the skin is more or less extensive, characterizing "limited" or "diffuse" SSc, respectively. SSc patients can present with internal organ involvement and organs such as lungs, heart, joints, digestive system or kidneys may be affected, with high morbidity/mortality (2). Skin involvement is assessed by the modified Rodnan skin score (mRSS), which reflects the severity of the disease and is a useful monitoring tool for the clinician (3). Skin involvement is also represented by Raynaud's phenomenon (95\% of cases) (2), sclerodactyly, telangiectasia (4), calcinosis (5), or pigmentation disorders (6). Facial involvement is characteristic with a possible loss of expression lines, loss of nasolabial fold and accentuation of perioral wrinkles, as well as wasting of temporal muscles and neck muscles. Management of these facial modifications includes $\mathrm{CO}_{2}$ laser techniques with a grade 4 level of evidence (7) or plastic surgery (8). To date, there is no curative treatment for the pathology. Obviously, skin involvement and especially facial localization of the disease can modify body image, with various consequences. 
The body image concept is defined as a mental image, describing both the physical and psychological personality that a person forges both by him- or herself and through others. Body image is not only aesthetic impairment. In studies assessing body image, the purpose is to objectively "measure" it through physical parameters, but also through psychic parameters (9). These interactions become more complex in the case of a pathology modifying a person's physical appearance. In such cases, patients more frequently and intricately report negative emotions (such as anxiety), negative thought mechanisms (such as excessive fear of pejorative evaluation), a negative self-concept (associating low self-esteem and negative self-image), and negative behaviors (such as social avoidance) (10). These considerations should be taken into account when evaluating body image of patients suffering from a chronic disease that can lead to profound changes in physical appearance, as is the case with SSc.

Benrud-Larson et al. (11) found a positive correlation between depressive symptoms and aesthetic impairment for patients with SSc assessed by the SWAP (Satisfaction With Appearance Scale) (12), an aesthetic impact questionnaire validated for a burn-injured population but not for patients with SSc. Correlations were significant between age, high SWAP scores (indicating dissatisfaction with self-image), and depressive symptoms. Kwakkenbos et al. (13) reported that fear of disease progression and low appearance self-esteem correlated with depression and appeared to be anxiety factors for patients with SSc. The prevalence of anxiety during SSc is correlated with digital ulcers (14). In the study by Amin et al. (15), changes in facial appearance were found to be correlated with both the Derriford Appearance Scale24 (DAS24), an aesthetic questionnaire not specific to SSc and with the score on the Hospital Anxiety and depression Scale (HADS). Out of 303 patients with SSc, $76 \%$ considered telangiectasia and $73 \%$ considered thin lips anxiogenic (16).

A meta-analysis by Thombs et al. (17) summarized the prevalence of depression in patients with SSc, as assessed in eight studies in various countries using different scales (BDI (Beck Depression Inventory), MADRS (Montgomery-Asberg Depression Rating Scale), CES-D (Center for Epidemiologic StudiesDepression Scale), HADS (Hospital Anxiety and Depression Scale), and DSSI/sAD (Delusions-SymptomsStates Inventory/states of Anxiety and Depression)). They all converged, however, towards a high prevalence of depressive symptoms during SSc; $46-65 \%$ with the BDI questionnaire, higher than in a population with severe burns (18), and $38 \%$ with the HADS questionnaire, higher than in other chronic inflammatory rheumatisms such as rheumatoid arthritis $(11-17 \%)(19,20)$.

Assessment of body image is crucially important in order to optimize patient care (21)(22) for patients with SSc. Nguyen et al. (23) investigated anxiety/depressive symptoms as main objective and quality of life, and aesthetic impairment as secondary objectives in SSc patients. The aesthetic evaluation scale (AES) used was a scale rated from 0 (no aesthetic impact) to 10 (maximum perception of aesthetic impairment). Heinberg et al. (24) worked on the validation of an aesthetic impact assessment questionnaire for patients with SSc. This is how the Adapted Satisfaction With Appearance (ASWAP) scale, resulting from the SWAP questionnaire, came to be evaluated showing internal consistency and temporal stability and strong evidence for the reliability without being used. There is no study, to our 
knowledge, which evaluates perception of aesthetic impairment as primary endpoint for patients with SSc.

The main objective of our study was to assess perception of aesthetic impairment in patients with SSc compared to a control group of healthy subjects using the AES of Nguyen et al. (23). Secondary objectives were: to assess associations between perception of aesthetic impairment, evaluated using the $A E S$, and standardized questionnaires for the assessment of aesthetic impact (including the ASWAP scale (24)) and to evaluate associations with clinical, biological, psychological, and functional parameters of SSc.

\section{Methods}

\section{Patients and procedures}

The "Sclero-esthet" study is a descriptive single-center epidemiological study that was performed in the Department of Internal Medicine, National Referral Center for systemic diseases and rare autoimmune diseases at Lille University Hospital, France, in 2017. Cases were consecutive patients with SSc seen in consultation or in scheduled hospitalization. Controls were healthy persons accompanying nonscleroderma patients. All consecutive participants were included, after oral and written information, according to their eligibility and after signing their informed consent. The promoter submitted an authorization request to the French National Agency for Medicines and Health Products Safety and obtained the favorable opinion of the ethics committee (Personal Protection Committee [CPP]) before the start of the research, in accordance with article L1121-4 of the French Public Health Code (registration number 2016 A0073546). The study is registered in Clinical Trials under number NCT03271320.

All participants had to be aged between 18 and 65 years. To be eligible for the study, patients had to have SSc meeting the ACR-EULAR 2013 criteria, regardless of severity. Patients with any of the following connective tissue diseases were not included: rheumatoid arthritis (25), Sjögren syndrome (26), systemic lupus erythematosus (27), Sharp syndrome (28). Controls with any connectivite tissue disease were not included. For all participants, any history of serious psychiatric pathology leading to hospitalizations in a psychiatric ward was considered a non-inclusion criterion, as was any reported acquired (e.g. burn) or congenital aesthetic malformation.

For all patients and controls included in the study, the following data were collected: demographic information (age, sex, number of children, tobacco use, level of education), current treatments, family history and lifestyle (marital status, occupation). For patients, an overall assessment of SSc was performed, which included the following: year of onset of Raynaud's phenomenon; year of the first manifestation of SSc other than Raynaud's phenomenon; treatment for SSc; skin involvement: modified Rodnan skin score (mRss), calcinosis, telangiectasia, skin ulcers; Medsger score; European Scleroderma Activity (EUSTAR) score; cardiopulmonary and digestive involvement.

\section{Measures:}


All participants completed the following self-administered questionnaires.

1. Evaluation of aesthetic impairment:

- The overall assessment of the perception of aesthetic impairment was, for both cases and controls, quantified by the $A E S$, a semi-quantitative scale ranging from 0 to 10 (the value 10 corresponding to a maximum alteration in their perception of aesthetic impairment) (23) worded as "Please rate what you consider to be the alteration in your aesthetic appearance by drawing a vertical line on the following scale".

- The ASWAP (Adapted Satisfaction With Appearance) scale questionnaire (24), divided into two parts: an individual's perception of each area of their body (8 items), and the social impact caused by their self-image ( 7 items). Scores range between 0 and 90 , with the highest values indicating maximum dissatisfaction. For the purposes of this study, the questionnaire was translated into French and then validated using a process of back-translation into English until the two versions matched.

- The DAS59 (Derriford Appearance Scale-59) questionnaire (29), comprising an overall assessment of appearance and an assessment focusing on physical discomfort reported by the subject. The questionnaire explores the following dimensions: General self-consciousness of appearance (GSC), Social self-consciousness of appearance (SCL), Sexual and bodily self-consciousness of appearance (SBSC), Negative self-concept (NSC), Facial self-consciousness of appearance (FSC), and Full-scale (FS). Scores for each category range from 0 to 5 , higher values reflecting maximum discomfort.

- The MBSRQ (Multidimensional Body-Self Relations Questionnaire) (30), comprising 34 items divided into the following subcategories: satisfaction with appearance, importance given to appearance, satisfaction with areas of the body, concerns about being overweight, self-classification of one's weight. This questionnaire (31) is an indicator of the subject's investment in their appearance, high values reflecting an individual's satisfaction with their self-image.

2. Anxiodepressive symptoms were assessed using the HADS (Hospital Anxiety and Depression Scale) questionnaire (32), comprising 14 items rated from 0 to 3 . These items are equally divided into two categories: anxiety symptoms and depressive symptoms. For each category, a total score over 7 (33) indicates the presence of that category of symptoms.

3. Self-esteem was assessed using the Rosenberg Self-Esteem questionnaire, comprising 10 items assessing either a negative or a positive view of oneself. Scores are between 10 and 40; values below 30 indicate low self-esteem (34).

4. Quality of life was assessed using:

The HAQ (Health Assessment Questionnaire) (35), assessing overall functional capacities across eight categories domains (clothing, body care; getting up; feeding; walking; hygiene; catching; grasping; others activities). The rating for each of the 8 categories is that corresponding to the highest score for the questions in that category. The score thus obtained is between 0 and 3 . The functional index is the sum 
of the ratings of the various categories divided by the number of categories assessed; the highest scores indicate maximum disability. The SHAQ has specific questions to evaluate the functional impact linked to symptoms of SSc (36).

The SF36 (36-item short-form health survey) (37), evaluating 8 dimensions: physical functioning, physical limitation, physical pain, general health, vitality, social functioning, emotional limitation, mental health. Each dimension is rated from 0 to 100 , with high values indicating a better health status.

\section{Statistical analysis}

Results were expressed as mean (standard deviation) or as median (interquartile range [IQR]) for quantitative variables, and number (percentage) for categorical variables. The normality of distribution was assessed graphically and using the Shapiro-Wilk test.

Comparisons between cases and controls were performed using the Mann-Whitney $\mathrm{U}$ test for quantitative or ordinal variables and the Chi-squared test (or Fisher's exact test when cell frequencies $<5$ ) for categorical variables. Comparisons were further adjusted for age and sex using analysis covariance (on rank-transformed data with non-Gaussian distribution) for quantitative variables and multiple logistic regression analysis for binary variables.

Statistical associations were performed using Pearson's correlation test or Spearman's rank correlation test (in cases of non-Gaussian distribution) for quantitative or ordinal variables and with the MannWhitney $\mathrm{U}$ test for categorical variables.

Associations and comparisons made are summarized in Figure 1.

Statistical testing was done at the two-tailed a level of 0.05. Data were analyzed using SAS software, Version 9.4 (SAS Institute, Cary, NC). We estimated the common standard deviation to be 3 at the AES between cases and controls. Under these conditions, with a power of $90 \%$ and an alpha risk of $5 \%$, we recruited 88 patients and 88 controls.

\section{Results}

Between January and October 2017, 88 patients (69 (78.4\%) women) with a median age of 52 years (43 to 59 ) were included, along with 88 controls (49 (55.7\%) women) with a median age of 45 (32 to 55$)$. Among the controls, 7 (8\%) were being followed up in the hospital's psychiatry department (but without hospitalization) (4 (4.5\%) for depression, 1 (1.1\%) for a bipolar disorder and 2 (2.3\%) for burnout); 2 (2.3\%) had psoriasis, one $(1.1 \%)$ had been operated for breast cancer, one $(1.1 \%)$ for bariatric surgery and one $(1.1 \%)$ for plastic surgery of the abdomen. Main characteristics of cases and controls are shown in Table 1. Cases were older, less often men, and less often in professional activity than controls. A significant difference in smoking status was also found, with cases being less often current smokers and more often former smokers than controls. Clinical characteristics of cases are summarized in Table 2. 
Table 1 Main characteristics of cases (SSc patients) and controls

\begin{tabular}{|llll|}
\hline Characteristics & $\begin{array}{l}\text { Cases } \\
(\mathbf{n}=88)\end{array}$ & $\begin{array}{l}\text { Controls } \\
(\mathbf{n}=88)\end{array}$ & P-Value \\
\hline Demographics & & & \\
\hline Age, years & $52(43$ to 59$)$ & $45(32$ to 55$)$ & 0.001 \\
\hline Men & $19 / 88(21.6)$ & $39 / 88(44.3)$ & 0.001 \\
\hline Civil status & & & \\
\hline child or more & $67 / 86(77.9)$ & $60 / 88(68.2)$ & 0.15 \\
\hline Couple & $66 / 86(76.7)$ & $66 / 88(75.0)$ & 0.79 \\
\hline Smoking status & & & \\
\hline Smoker & $15 / 88(17.1)$ & $22 / 87(25.3)$ & 0.047 \\
Former smoker & $25 / 88(28.4)$ & $12 / 87(13.8)$ & \\
Non-smoker & $48 / 88(54.5)$ & $53 / 87(60.9)$ & \\
\hline Professional status & & & \\
\hline Professionally active & & & \\
On sick leave & $41 / 88(46.6)$ & $75 / 88(85.2)$ & $<0.001$ \\
Disabled & $7 / 88(7.9)$ & $1 / 88(1.1)$ & \\
Retired & $15 / 88(17.0)$ & $2 / 88(2.3)$ & \\
Inactive & $13 / 88(14.8)$ & $8 / 88(9.1)$ & \\
\hline & $12 / 88(13.6)$ & $2 / 88(2.3)$ & \\
Among those professionally active: Employees & $24 / 41(58.5)$ & $40 / 75(53.3)$ & 0.59 \\
\hline
\end{tabular}

Values are no./No (\%) or median (interquartile range)

Table 2 Clinical characteristics of cases 


\begin{tabular}{|lll|}
\hline Variable & & SSc patients $(\mathbf{n}=\mathbf{8 8})$ \\
\hline No. years since diagnosis & Less than 5 years & $22 / 86(25.6)$ \\
\cline { 2 - 3 } & Between 5 and 10 years & $27 / 86(31.4)$ \\
\cline { 2 - 3 } & More than 10 years & $37 / 86(43.0)$ \\
\hline Raynaud's phenomenon & & $86 / 86(100)$ \\
\hline Type of SSc & Limited cutaneous & $56 / 86(65.1)$ \\
\cline { 2 - 3 } & Diffuse & $25 / 86(29.1)$ \\
\cline { 2 - 3 } & Sine scleroderma & $5 / 86(5.8)$ \\
\hline Mean mRSS & Limited SSc & $3(2$ to 6) \\
\cline { 2 - 3 } & Diffuse SSc & $8(5$ to 11$)$ \\
\hline Calcinosis & & $12 / 82(14.6)$ \\
\hline Digital ulcers & & $24 / 83(28.9)$ \\
\hline Telangiectasias & & $58 / 84(69.0)$ \\
\hline Lip wrinkles & & $59 / 88(67.0)$ \\
\hline Average vertical inter-incisor measurement (mm) & $42.3 \pm 11.1$ \\
\hline Medsger score ${ }^{1}$ & & $4(2$ to 5$)$ \\
\hline EUSTAR score ${ }^{2}$ & & $0.5(0.5$ to 1$)$ \\
\hline
\end{tabular}

${ }^{1} 6$ missing values, ${ }^{2} 5$ missing values, ${ }^{3} 1$ missing value

\section{Comparisons between cases and controls}

All participant completed the entire questionnaire without missing data. As shown in Table 3, concerning the main objective of the study, SSc patients had a higher AES score than controls ( $3.7 \pm 0.3$ vs $2.8 \pm 0.3$, $p=0.028$ after adjustment for age and sex). Quality of life, anxiety/depressive symptoms, and self-esteem also differed between cases by comparison to controls. Sixty-two $(70.5 \%)$ cases experienced physical discomfort, which for 31 (50\%) patients concerned the face, for 17 (27.4\%) the hands, and for 14 (22.6\%) areas potentially not visible to others. Regarding quality of life assessment, cases presented poorer quality of life than controls, with all dimensions except social functioning and emotional well-being differing significantly between the two groups. Self-esteem was considered pathological in $44.2 \%$ of cases, compared to $23.9 \%$ in controls ( $p=0.027$ after adjustment for age and sex). 
Table 3 Comparison of aesthetic assessment, quality of life, anxiety/depressive symptoms, and selfesteem analysis between cases and controls

\begin{tabular}{|c|c|c|c|}
\hline Outcomes & $\begin{array}{l}\text { SSc cases } \\
(n=88)\end{array}$ & $\begin{array}{l}\text { Controls } \\
(n=88)\end{array}$ & $P$ Value ${ }^{1 / 2}$ \\
\hline AES & $3.7 \pm 0.3$ & $2.8 \pm 0.3$ & $0.003 / 0.028$ \\
\hline \multicolumn{4}{|l|}{ Quality of life } \\
\hline HAQ scores & $0.4 \pm 0.05$ & $0.04 \pm 0.05$ & $<0.001 /<0.001$ \\
\hline \multicolumn{4}{|l|}{ SF36 questionnaire scores ${ }^{3}$} \\
\hline Physical functioning & $68.2 \pm 3.0$ & $86.8 \pm 2.7$ & $<0.001<0.001$ \\
\hline Role limitations due to physical health & $65.5 \pm 3.3$ & $80.2 \pm 2.9$ & $<0.001 / 0.001$ \\
\hline Pain & $53.7 \pm 2.2$ & $59.9 \pm 1.9$ & $0.019 / 0.035$ \\
\hline General health & $49.0 \pm 2.0$ & $65.1 \pm 1.8$ & $<0.001<0.001$ \\
\hline Energy & $53.6 \pm 2.4$ & $64.4 \pm 2.1$ & $<0.001 / 0.001$ \\
\hline Social functioning & $76.9 \pm 2.9$ & $75.9 \pm 2.6$ & $0.34 / 0.92$ \\
\hline $\begin{array}{l}\text { Role limitations due to emotional } \\
\text { problems }\end{array}$ & $70.9 \pm 3.1$ & $81.8 \pm 2.8$ & $<0.001 / 0.011$ \\
\hline Emotional well-being & $62.7 \pm 2.5$ & $66.7 \pm 2.3$ & $0.07 / 0.24$ \\
\hline SF36 PHYSICAL SCORE & $59.1 \pm 2.0$ & $72.9 \pm 1.8$ & $<0.001<0.001$ \\
\hline SF36 MENTAL SCORE & $66.0 \pm 2.4$ & $72.2 \pm 2.1$ & $0.005 / 0.055$ \\
\hline \multicolumn{4}{|l|}{ Anxiety and depressive symptoms } \\
\hline HADS anxious symptoms & $51 / 86(59.3 \%)$ & $36 / 88(40.9 \%)$ & $0.015 / 0.26$ \\
\hline HADS depressive symptoms & $23 / 86(26.7 \%)$ & $9 / 88(10.2 \%)$ & $0.005 / 0.021$ \\
\hline \multicolumn{4}{|l|}{ Self-esteem (Rosenberg) } \\
\hline Pathological & $38 / 86(44.2 \%)$ & $21 / 88(23.9 \%)$ & $0.005 / 0.027$ \\
\hline
\end{tabular}

${ }^{1}$ Unadjusted P-values; ${ }^{2}$ Age-sex-adjusted P-values. ${ }^{3} 3$ missing values in SSc cases.

Values are no./No (\%) or mean \pm standard deviation, median (interquartile range) with mean \pm standard deviation adjusted.

\section{Association of AES and other scoring evaluation in cases}


We found a significant positive correlation between AES scores and ASWAP ( $r=0.55)$, as well as with the DAS59 questionnaire $(r=0.30)$. Regarding the dimensions evaluated by DAS59, the strongest correlation was found for general self-consciousness of appearance $(r=0.37)$. However, no correlation was found between AES scores and the MBRSQ questionnaire; only a weak negative correlation was found with satisfaction with areas of the body $(r=-0.26)$. AES score were also positively associated with both presence of anxiety symptoms and presence of depressive symptoms (Table 4).

Table 4 Association of AES with other evaluations (aesthetic evaluation, anxiety/depressive symptoms, self-esteem) in SSc cases 


\section{Values}

Correlation with

AES (r)

\section{Esthetic evaluation}

\begin{tabular}{|c|c|c|c|}
\hline ASWAP & $\begin{array}{l}38.9 \pm \\
17.5\end{array}$ & 0.55 & $<.0001$ \\
\hline \multicolumn{4}{|l|}{ DAS59 } \\
\hline Full-Scale (FS) & $1.6 \pm 0.6$ & 0.30 & 0.005 \\
\hline General self-consciousness of appearance (GSC) & $1.5 \pm 0.8$ & 0.37 & 0.0005 \\
\hline Social self-consciousness of appearance (SCL) & $1.0 \pm 0.7$ & 0.18 & 0.09 \\
\hline $\begin{array}{l}\text { Sexual and bodily self-consciousness of appearance } \\
\text { (SBSC) }\end{array}$ & $1.3 \pm 0.8$ & 0.18 & 0.11 \\
\hline Negative self-concept (NSC) & $1.9 \pm 0.7$ & 0.20 & 0.06 \\
\hline Facial self-consciousness of appearance (FSC) & $1.4 \pm 1.1$ & 0.15 & 0.17 \\
\hline \multicolumn{4}{|l|}{ MBSRQ } \\
\hline Satisfaction with appearance & $3.0 \pm 0.7$ & -0.10 & 0.35 \\
\hline Importance given to appearance & $3.6 \pm 0.6$ & 0.10 & 0.33 \\
\hline Satisfaction with areas of the body & $2.8 \pm 0.7$ & -0.26 & 0.016 \\
\hline Concerns about being overweight & $2.6 \pm 0.8$ & 0.20 & 0.06 \\
\hline \multirow[t]{2}{*}{ Self-classification of one's weight } & $3.3 \pm 0.9$ & -0.06 & 0.59 \\
\hline & Values & $\begin{array}{l}\text { Median AES score } \\
\text { (IQR) }\end{array}$ & $\begin{array}{l}P \text { - } \\
\text { Value }\end{array}$ \\
\hline \multicolumn{4}{|l|}{ Anxiety/depressive symptoms } \\
\hline Anxious symptoms: Yes & $\begin{array}{l}51 / 86 \\
(59.3)\end{array}$ & 5.0 (2.5 to 6.5$)$ & 0.002 \\
\hline No & $\begin{array}{l}35 / 86 \\
(40.7)\end{array}$ & $2.2(0.5$ to 4.0$)$ & \\
\hline Depressive symptoms: Yes & $\begin{array}{l}23 / 86 \\
(26.7)\end{array}$ & $5.0(2.5$ to 6.9$)$ & 0.029 \\
\hline No & $\begin{array}{l}63 / 86 \\
(73.3)\end{array}$ & 3.0 (1.0 to 5.5$)$ & \\
\hline
\end{tabular}

\section{Self-esteem (Rosenberg)}


Values are descriptive parameters of evaluation other than AES scores; mean \pm SD, median (IQR) or no./No.(\%) are reported.

\section{Association of AES scores and clinical characteristics of SSC}

A statistically significant difference was found between the AES scores of patients with perioral radiated wrinkles and those without (respectively, median [IQR]: 4.5 [2.5 to 6] and 2.2 [ 1 to 5 ], $p=0.045$ ), as well as between patients with pitting scars and those without (respectively, median [IQR]: 5 [3.5 to 7] and 3 [1 to 5.85], $p=0.027$ ) (data not shown). There was a statistical tendency for a difference between the AES scores of patients with telangiectasias and those without $(p=0.053)$. There was no difference in the distribution of AES scores between patients with the limited cutaneous form and those with the diffuse form of SSc nor was there an association with the mRSS. We did not find a significant association between AES scores and the following: other clinical characteristics of SSc: calcinosis, ulcers, vertical interincisor measurement; the Medsger score; the EUSTAR score; and visceral lesions related to SSc (cardiopulmonary, digestive impairment).

\section{Discussion}

SSc is a chronic autoimmune disease resulting in fibrosis of the dermis, which induces visible and palpable modification of the skin. We assessed perception of these physical changes using the AES, which was the primary endpoint of the study. Using this scale, we showed that SSc patients presented a greater perception of aesthetic impairment than controls. Results at the AES were correlated with results at the ASWAP, a specific questionnaire not yet used in literature for the evaluation of aesthetic impairment in SSc. The AES results were correlated with symptoms of anxiety and depression. Patients presented poorer quality of life than controls. AES then appeared as an ease tool to evaluate body image for patients with SSc and not only perception of aesthetic impairment.

Body image is not limited to a mental body image and must also take into account cognitive, and behavioral dimensions (38). This is how Thompson (39) defined methodological strategies in bodyimage studies, insisting on the choice of general versus specific questionnaires as well as on the components that should be evaluated. This is how we chose the following three questionnaires: the DAS59 for its mixed assessment, both global and focused on a physical complex; the ASWAP for its specificity with SSc, and the MBSRQ for assessing an individual's investment in their appearance.

The AES is a rapid and ease assessment tool for measuring aesthetic impairment associated with SSc. 
The results of ASWAP questionnaire, the only aesthetic evaluation questionnaire specific to SSc, were correlated with those of the AES. Even though this questionnaire has already been validated in the literature (24), it has, as far as we are aware, never been used. The AES was correlated with the overall "Full scale" score of the DAS59, one of the benchmark tests for evaluating aesthetic impairment.

Evaluation of the discomfort felt by patients revealed essentially discomfort of the face and hands, with a description compatible with dermatological lesions of SSc ("red spots on face, swollen hands, wrinkles around the lips"). However, DAS59 questions on the Assessment of Investment in Facial Aesthetics (FSC) were not significantly correlated with the AES. This could be explained by the fact that questions in this category relate to elements not adapted to the patient's experience in the case of SSc (29), with questions on propositions such as: "you are unable to change your hair style or you avoid having wet hair".

\section{The AES correlates with visible signs of SSc.}

The presence of radiated folds was correlated with the results of the AES. This suggests that visible damage could be the most disturbing for patients, tying in with the body image concept as defined in the literature with others' approval concerns predicting body concerns (40). Although not quantifiable, physical complexes reported in the DAS59 were also visible signs, namely damage to face and hands. The AES was used in a study to evaluate the aesthetic impact of digital ulcers; patients with digital ulcers had higher scores than patients without (41). We did not find a correlation between clinical signs of the disease (calcinosis, telangiectasias, MRSS score) and the AES. Yet, the prevalence of these complications was quite low and our study may have lacked the power to find a significant correlation. Likewise, disease activity scores or internal organ involvement did not correlate with AES, suggesting that visceral involvement does not deeply impact body image.

\section{Correlations with psychological parameters makes the AES an ease tool to evaluate body image.}

In 2014, Nguyen et al. (23) evaluated the aesthetic impact in patients with SSc using the same scale, but without a control group. The median score in their study was $5(3-7)$, a value close to that of our study, namely 3.9 (1.55-6). Their study focused on the evaluation of anxiety/depressive symptoms in patients with SSc; aesthetic evaluation was therefore secondary but still allowed them to reveal a previously unknown aspect of management of the disease. Perception of aesthetic alteration appears not only to be linked to visible aspects of the disease but is also underpinned by notions including a psychological aspect relating to the image of self-returned to society. Thus, it was important to assess anxiety/depressive symptoms and self-esteem. Prevalence of depressive symptoms, as assessed by the HADS score, was significantly higher in cases than in controls, with values comparable to those in the literature (42). We did not find differences in anxiety symptoms between the two groups. The prevalence of anxiety symptoms found in controls in our study was higher than that reported in the general population (43), possibly explained by hospital recruitment (44). Psychological impairment during SSc therefore does not seem marginal in self-image assessment. Thombs et al. (18) showed in a severe burns population that self-image contributed to depressive symptoms years after the trauma caused by the accident and despite surgical management. As SSc is a chronic disease, the influence of depression on 
body image and its reciprocity is more complex to define, due to the slow progression of the disease. A follow-up over time of anxiety and depression in patients with SSc could provide some answers.

The image of oneself, when it is related to physical identity, is therefore assimilated to the image that our body sends back to us and to the interpretation that we make of it. Psychologically, it is related to selfesteem, which depends on the degree of cohesion between aspirations and reality at a given time. In our study, SSc cases had lower self-esteem than controls. It has already been shown that there is a strong link between self-esteem, acceptance of the disease and coping in people with SSc (45)(46). Van Lankveld et al. (45) also found that "active" coping-type, that is to say, problem-oriented coping methods, was ssociated with improved self-esteem in patients with SSc (46). It would be interesting to evaluate strategies developed by patients in our study to adapt to aesthetic changes induced by the disease. Van Lankveld et al. (45) also looked at cognitive capacities of patients with SSc, and in particular the processes by which an individual acquires awareness of a disease; they found that a better acceptance of the disease was related to better self-esteem. This finding could explain the lack of correlation in our study between the scores on the Rosenberg self-Esteem questionnaire and the results on the AES. We therefore see the importance of interlocking cognitive processes and strategies developed by an individual faced with changes in their appearance.

As these processes are also influenced by the patient's environment, patients had higher scores than healthy subjects on the HAQ questionnaire. This reflects the physical limitations induced by the disease, as shown in the study of Poole et al. (47). In our study, the physical limitations of SSc cases, as measured by the HAQ questionnaire, were statistically significant compared to controls. These limitations, impacting quality of life, introduce the notion of "disabling disease", which can give rise to a situation of disability (48). However, aesthetic impairment in connection with a chronic pathology such as SSc is not yet recognized as an aesthetic disability, although it meets the definition.

Our study has limitations. It was a single-center study, based on voluntary participation, thus introducing a potential bias in self-selection of cases or controls. This risk was partly controlled by exclusion of participants with acquired or congenital aesthetic defects or a history of serious psychiatric disorders leading to hospitalization. In addition, hospital recruitment of patients and controls created a possible admission bias. This can lead to an overestimation of parameters, in particular anxiety/depressive symptoms. The number of subjects included (176 in total) is a sufficiently representative sample of the two populations. The systematic comparison with the control group is the main strength of this study, allowing us to analyze correlations between the parameters evaluated. Older age and higher proportion of males among controls may introduce a bias in body image evaluation which was partially remove with statistical adjustment. In our study, we evaluated all parameters at a given time, which did not allow us to analyze the questionnaires' sensitivity to change. Prospective longitudinal studies are needed to assess causal links between aesthetic impact during SSc and psychological aspects, especially since body image is generally not very resistant to change (49). The choice of questionnaires can also be discussed. Indeed, the HADS questionnaire and the Rosenberg Self-Esteem Questionnaire are aimed at screening for psychological disorders. They cannot replace structured interviews by a specialist in the analysis of the 
disorder. However, our data on anxiety and depressive symptoms in patients with SSc remain superimposable on the prevalence reported in the literature. Our results could usefully be enriched by additional tests such as patient's coping strategies and personality traits (45).

\section{Conclusion}

Perception of aesthetic impairment assessed using the AES was poorer in patients than healthy individuals. AES appeared to be a good evaluator of body image in patients with SSc, reflecting dissatisfaction linked to psychological, social, and functional dimensions. AES could thus become a tool to be used during clinical assessment to better meet the needs of patients, both physically and through individualized psychological care.

\section{Declarations}

\section{Ethical Approval and Consent to participate}

All procedures performed in studies involving human participants were in accordance with the ethical standards of the institutional and/or national research committee and with the 1964 Helsinki declaration and its later amendments or comparable ethical standards. Informed consent was obtained from all individual participants included in the study.

\section{Consent for publication}

I, Méryem-Maud Farhat give my consent for information about myself and all authors to be published in Arthristis Research\&Therapy, manuscript number ARRT-D-21-00393, Farhat. I understand that the information will be published without my name attached, but that full anonymity cannot be guaranteed. I understand that the text and any pictures or videos published in the article will be freely available on the internet and may be seen by the general public. The pictures, videos and text may also appear on other websites or in print, may be translated into other languages or used for commercial purposes. I have been offered the opportunity to read the manuscript.

\section{Availability of supporting data}

We have full control of all primary data and we agree to allow the journal to review our data upon request

\section{Competing interests}

The authors declare that they have no conflict of interest.

\section{Funding}

Not applicable

\section{Authors' contributions}


MMF and DL Methodology and Investigation. MMF, PG, SM-D, SS, VS, EH, OC and DL Review and Editing. MMF, VD, JL and DL Statistical analysis.

\section{Acknowledgements}

We are grateful to participants for their contribution to this work.

\section{Authors' information}

Dr Méryem-Maud Farhat, meryem.farhat@chu-lille.fr; CHU Lille, Service de Médecine Interne et Immunologie Clinique, Centre de référence des maladies autoimmunes systémiques rares du Nord et Nord-Ouest de France (CeRAINO), F-59000 Lille, France

\section{References}

1. Le Guern V. Prevalence of systemic sclerosis in a French multi-ethnic county. Rheumatology. 2004;43(9):1129-37.

2. Hachulla E, Launay D. Sclérodermie systémique. EMC - Rhumatol-Orthopédie. 2005;2:479-500.

3. Van den Hoogen F, Khanna D, Fransen J, Johnson SR, Baron M, Tyndall A, et al. Classification Criteria for Systemic Sclerosis: An ACR-EULAR Collaborative Initiative. Arthritis Rheum. 2013;65(11):2737-47.

4. Ciatti S, Varga J, Greenbaum SS. The $585 \mathrm{~nm}$ flashlamp-pumped pulsed dye laser for the treatment of telangiectases in patients with scleroderma. J Am Acad Dermatol. 1996;35(3):487-8.

5. Merlino G, Germano S, Carlucci S. Surgical Management of Digital Calcinosis in CREST Syndrome. Aesth Plast Surg.2013;37(6):1214-9..

6. Leroy-Colavolpe V. Évaluation des troubles de la pigmentation dans la sclérodermie systémique: étude rétrospective d'une cohorte de 239 patients. 2017;79. .

7. Alantar A, Cabane J, Hachulla E, Princ G, Ginisty D, Hassin M. Recommendations for the care of oral involvement in patients with systemic sclerosis. Arthritis Care Res 2011;63(8):1126-33.

8. Coleman S. Long-Term survival of fat transplants: Controlled demonstrations. Aesth Plast Surg $1995 ; 19(5): 421-5$.

9. Cash TF. Body image: past, present, and future. Body Image 2004;1(1):1-5.

10. Rumsey N, Clarke A, Musa M. Altered body image: the psychosocial needs of patients. $\mathrm{Br} \mathrm{J}$ Community Nurs. 2002;7(11):563-6.

11. Benrud-Larson LM, Heinberg LJ, Boling C, Reed J, White B, Wigley FM. Body image dissatisfaction among women with scleroderma: extent and relationship to psychosocial function. Health Psychol. 2003;22(2):130-9.

12. Lawrence JW, Heinberg LJ, Roca R, Munster A, Spence R, Fauerbach JA. Development and validation of the Satisfaction With Appearance Scale: Assessing body image among burn-injured patients. Psychol Assess. 1998;10(1):64-70. 
13. Kwakkenbos L, Van Lankveld WGJM, Vonk MC, Becker ES, Hoogen FHJ, Ende CHM. Disease-related and psychosocial factors associated with depressive symptoms in patients with systemic sclerosis, including fear of progression and appearance self-esteem. J Psychosom Res. 2012;72(3):199-204.

14. Leon L, Abasolo L, Redondo M, Perez-Nieto MA, Rodriguez-Rodriguez L, Casado MI. Negative affect in systemic sclerosis. Rheumatol Int 2014;34(5):597-604.

15. Amin K, Clarke A, Sivakumar B, Puri A, Fox Z, Brough V. The psychological impact of facial changes in scleroderma. Psychol Health Med 2011;16(3):304-12.

16. Paquette DL, Falanga V. Cutaneous Concerns of Scleroderma Patients. J Dermatol. 2014;30(6):438-43.

17. Thombs BD, Taillefer SS., Hudson M, Baron M. Depression in patients with systemic sclerosis: A systematic review of the evidence. Arthritis Care Res 2007;57(6):1089-97.

18. Thombs BD, Haines JM, Bresnick MG, Magyar-Russell G, Fauerbach JA, Spence RJ. Depression in burn reconstruction patients: symptom prevalence and association with body image dissatisfaction and physical function. Gen Hosp Psychiatry 2007;29(1):14-20.

19. Murphy H, Dickens C, Creed F, Bernstein R. Depression, illness perception and coping in rheumatoid arthritis. J Psychosom Res. 1999;46(2):155-64.

20. Pincus T, Griffith J, Pearce S, Isenberg D. Prevalence of self-reported depression in patients with rheumatoid arthritis. Br J Rheumatol 1996;35(9):879-83.

21. Thombs BD, Jewett LR, Assassi S, Baron M, Bartlett SJ, Costa Maia A. New directions for patientcentred care in scleroderma: the Scleroderma Patient-centred Intervention Network (SPIN. Clin Exp Rheumatol. 2012;30(2 0 71).

22. Schouffoer AA, Zirkzee EJM, Henquet SM, Caljouw MAA, Steup-Beekman GM, Van Laar JM. Needs and preferences regarding health care delivery as perceived by patients with systemic sclerosis. Clin Rheumatol. 2011;30(6):815-24.

23. Nguyen C, Ranque B, Baubet T, Bérezné A, Mestre-Stanislas C, Rannou F, et al. Clinical, Functional and Health-Related Quality of Life Correlates of Clinically Significant Symptoms of Anxiety and Depression in Patients with Systemic Sclerosis: A Cross-Sectional Survey. PLoS ONE

24. Heinberg LJ, Kudel I, White B, Kwan A, Medley K, Wigley F. Assessing body image in patients with systemic sclerosis (scleroderma): Validation of the Adapted Satisfaction with Appearance Scale. Body Image 2007;4(1):79-86.

25. Arnett FC, Edworthy SM, Bloch DA, McShane DJ, Fries JF, Cooper NS. The American Rheumatism Association 1987 revised criteria for the classification of rheumatoid arthritis. Arthritis Rheum 1988;31(3):315-24.

26. Vitali C, Bombardieri S, Moutsopoulos HM, Coll J, Gerli R, Hatron PY. Assessment of the European classification criteria for Sjögren's syndrome in a series of clinically defined cases: results of a prospective multicentre study. Eur Study Group Diagn Criteria Sjögren's Syndr Ann Rheum1996;55(2):116-21. 
27. Hochberg MC. Updating the American College of Rheumatology revised criteria for the classification of systemic lupus erythematosus. Arthritis Rheum 1997;40(9).

28. Alarcón-Segovia D. Mixed connective tissue disease and overlap syndromes. Clin Dermatol 1994;12(2):309-16.

29. Harris DL, Carr AT. The Derriford Appearance Scale (DAS59): a new psychometric scale for the evaluation of patients with disfigurements and aesthetic problems of appearance. Br J Plast Surg. 2001;54(3):216-22.

30. Cash T. Multidimensional Body-Self Relations Questionnaire (MBSRQ. 2017. 551-5 p.

31. Untas A, Koleck M, Rascle N, Borteyrou X. Psychometric Properties of the French Adaptation of the Multidimensional Body Self Relations Questionnaire-Appearance Scales. Psychol Rep 2009;105(2):461-71.

32. Zigmond AS, Snaith RP. The Hospital Anxiety and Depression Scale. Acta Psychiatr Scand. 1983;67(6):361-70.

33. Stern AF. The Hospital Anxiety and Depression Scale. Occup Med Lond 2014;64(5):393-4.

34. Sinclair SJ, Blais MA, Gansler DA, Sandberg E, Bistis K, LoCicero A. Psychometric Properties of the Rosenberg Self-Esteem Scale: Overall and Across Demographic Groups Living Within the United States. Eval Health Prof 2010;33(1):56-80.

35. Bruce B, Fries JF. The Stanford Health Assessment Questionnaire: a review of its history, issues, progress, and documentation. J Rheumatol 2003;30(1):167-78.

36. Steen VD, Medsger TA. The value of the Health Assessment Questionnaire and special patientgenerated scales to demonstrate change in systemic sclerosis patients over time. Arthritis Rheum. 1997;40(11):1984-91.

37. Ware J, Sherbourne C. The MOS 36-item short-form health survey (SF-36). Conceptual framework and item selection. Med Care 1992;30(6):473-83.

38. Piolat M, Hurtig MC, Pichevin MF. Le soi : recherche dans le champ de la cognition sociale. 1992.

39. Thompson JK. The (mis)measurement of body image: ten strategies to improve assessment for applied and research purposes. Body Image 2004;1(1):7-14.

40. IP SFH. Perceptual and Cognitive Aspects of Body Experience. Sci 1970;168(3933):813-4.

41. Impact of digital ulcers on disability and health-related quality of life in systemic sclerosis. Ann Rheum Dis 2010;69(01):214-7.

42. Atteintes neuropsychiatriques au cours de la sclérodermie systémique. Presse Med 2010;39(5):539-47.

43. Ritchie K, Artero S, Beluche I, Ancelin M-L, Mann A, Dupuy A-M. Prevalence of DSM-IV psychiatric disorder in the French elderly population. Br J Psychiatry 2004;184(02):147-52.

44. Azoulay E, Pochard F, Chevret S, Arich C, Brivet F, Brun F. Family participation in care to the critically ill: opinions of families and staff. Intensive Care Med 2003;29(9):1498-504. 
45. WG VL, MC V, H T, FH VDH. Appearance self-esteem in systemic sclerosis-subjective experience of skin deformity and its relationship with physician-assessed skin involvement, disease status and psychological variables. Rheumatol Oxf 2007;46(5):872-6.

46. Folkman S. Stress: Appraisal and Coping. In: Encyclopedia of Behavioral Medicine. Springer; 2013. p. 1913-5.

47. Poole JL, Steen Virginia D. The use of the health assessment questionnaire (HAQ) to determine physical disability in systemic sclerosis. Arthritis Rheum. 2005;4(1):27-31.

48. Loi n² 2005-102 du 11 février 2005 pour l'égalité des droits et des chances, la participation et la citoyenneté des personnes handicapées.

49. Murray SL, Griffin DW, Rose P, Bellavia GM. Calibrating the sociometer: the relational contingencies of self-esteem. J Soc Psychol 2003;85(1):63-84.

\section{Figures}




\section{Questionnaire}

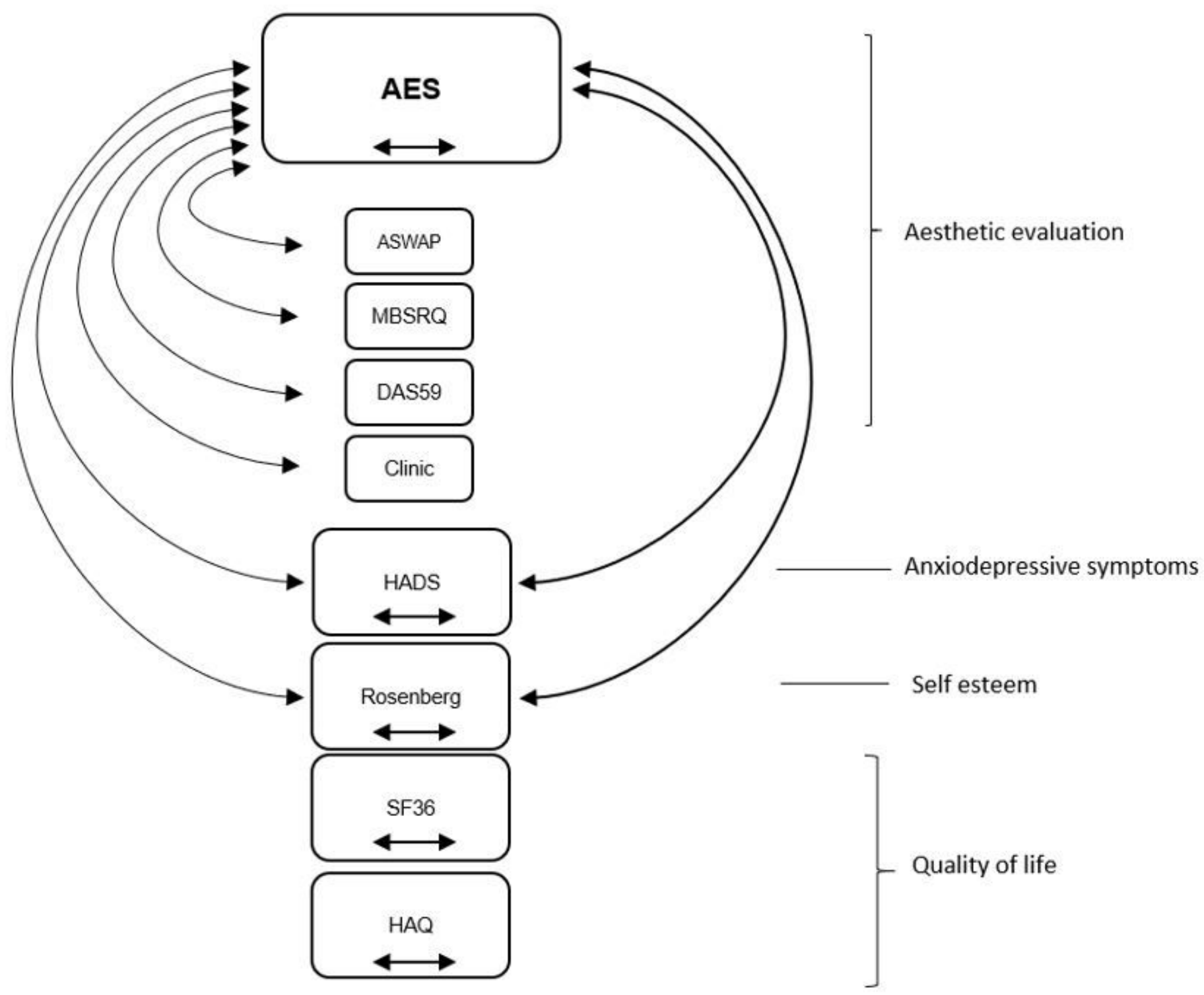

\section{Figure 1}

Representation of intra-group correlations and inter-group analysis. Side arrows indicate statistical correlations made. Horizontal arrows indicate comparisons made between cases and controls. 